\title{
High-field and benchtop NMR spectroscopy for the characterization of new psychoactive substances
}

Thomas Castaing-Cordier ${ }^{a}$, Virginie Ladroue $^{b}$, Fabrice Besacier ${ }^{b}$, Audrey Bulete ${ }^{b}$ Denis Jacquemin ${ }^{\mathrm{a}}$, Patrick Giraudeau a and Jonathan Farjon ${ }^{\mathrm{a},}{ }^{*}$

aUniversité de Nantes, CNRS, CEISAM UMR 6230, F-44000 Nantes, France

bInstitut National de Police Scientifique (INPS), Laboratoire de Lyon (LPS69), 69134 Ecully, France

*Corresponding author: jonathan.farjon@univ-nantes.fr

Abstract:

New psychoactive substances (NPS) have become a serious threat for public health in Europe due to their ability to be sold in the street or on the darknet. Regulating NPS is an urgent priority but comes with a number of analytical challenges since they are structurally close to legal products. A number of analytical techniques can be used for identifying NPS, among which NMR spectroscopy is in the limelight. High field NMR is typically used for structural elucidation in combination with others techniques like GC-MS, Infrared spectroscopy, together with databases. In addition to their strong ability to elucidate molecular structures, high field NMR techniques are the gold standard for quantification without any physical isolation procedure and with a single internal standard. However, high field NMR remains expensive and emerging "benchtop" NMR apparatus which are cheaper and transportable can be considered as valuable alternatives to high field NMR. Indeed, benchtop NMR, which has emerged about ten years ago, makes it possible to carry out structural elucidation and quantification of new psychoactive substances despite the gap in resolution and sensitivity as compared to high field NMR. This review describes recent advances in the field of NMR applied to the characterization of NPS. High-field NMR methods are first described in view of their complementarity with other analytical methods, focusing on both structural and quantitative aspects. The second part of the review highlights how emerging benchtop NMR approaches could act as a game changer in the field of forensics.

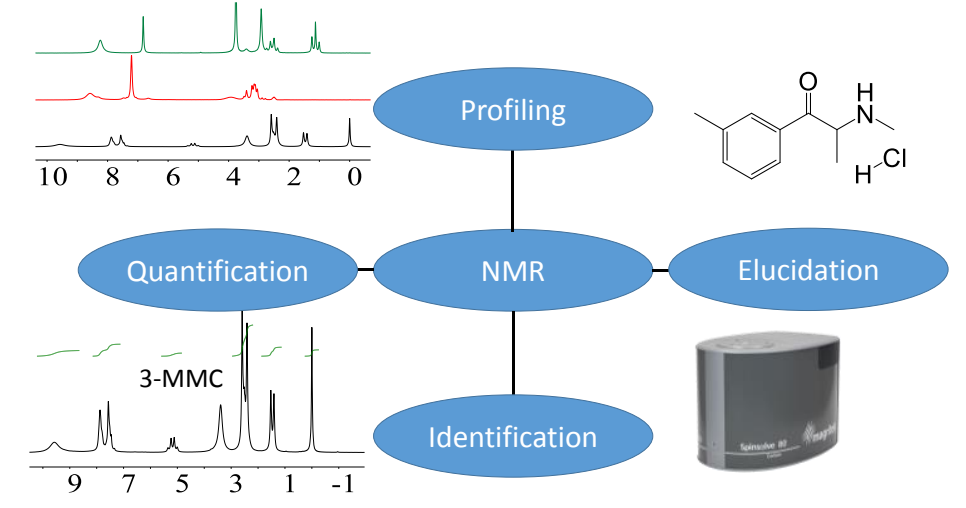

Graphical abstract: what information can NMR bring for forensics? 
Keywords: New Psychoactive Substances, High Field NMR spectroscopy, benchtop NMR spectrometer, structure elucidation, quantification. 
- New psychoactive substances are a serious threat for public health

- These drugs are sold in the street or the darknet and need an urgent identification

- Nuclear Magnetic Resonance is a gold standard for elucidation and quantification

- Complementarity of other analytical techniques is essential to elucidate drugs

- Benchtop Nuclear Magnetic Resonance is an emerging mobile approach for forensics 


\section{Introduction}

New psychoactive substances (NPS) gather different families of molecules such as aminoindanes, synthetic cannabinoids, synthetic cathinones, phenethylamnines, piperazines, tryptamines, and plant-based substances (Figure 1) [1]. NPS are molecules derived from scheduled or commercial drugs which have been misused or whose structure has been slightly modified. As a consequence of these chemical modifications, these hazardous compounds are not always controlled under the International Drug Control Conventions, and their legal status remains undefined. Since 1997, 450 NPS have been reported in Europe, and among them two thirds since 2008 [2]. NPS are usually purchased on the darknet but also in the street [3]. The growing occurrence of these molecules on the European market is an alarming threat for public health because they are widely consumed during festive events as recreational drugs and their use could lead to death by overdose. In this context, there is an urgent need to develop robust and high-throughput analytical tools to help reporting NPS. In particular, methods are needed to identify the molecular structure of known NPS and to elucidate the structure of unknown compounds that appear on the market, either as pure molecules or in mixtures.
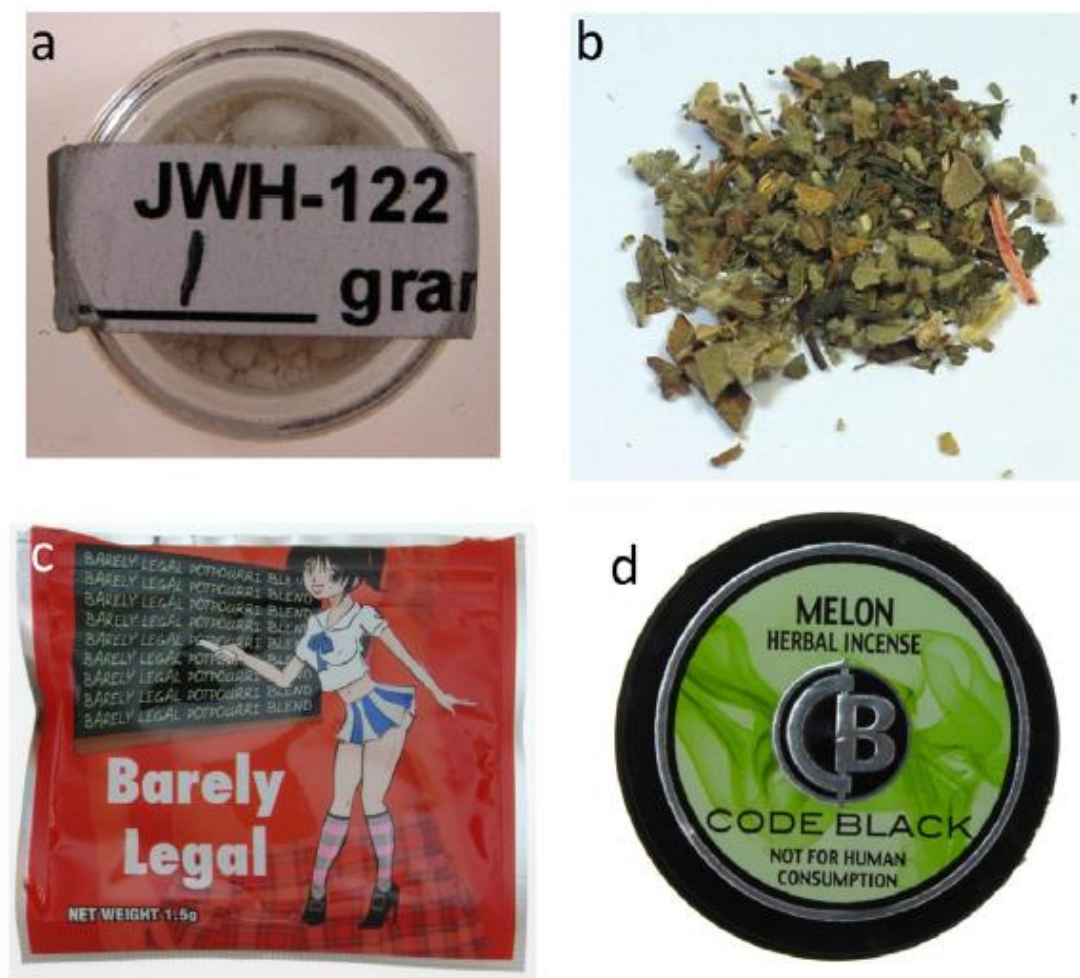

Figure 1: Various Spice products (a) "Mountain Industry"; (b) JWH-122 powder; "Moon Spice", leaf; (c) "Barely Legal”, "Spice” package; (d) "Melon Code Black", "Spice” package. Reproduced from Ref. [3] with permission.

Several experimental techniques are commonly used to characterize the structure of NPS. First, InfraRed (IR) and Raman spectroscopies, the most widespread optical techniques, are tools of choice to determine the chemical functions of the molecule under study [4]. In addition, different variants of Mass Spectrometry (MS) coupled to chromatography are also widely used. MS, with Chemical Ionization $(\mathrm{Cl})$ is used to provide the molecular weight [5]. In addition, MS with Electronic Impact (EI) mode is able to provide information on different 
fragments of the molecule [5]. Hyphenated MS-MS or $\mathrm{MS}^{2}$ makes it possible to get further insight into fragmentation schemes of the molecule [6]. Finally, High Resolution Mass Spectrometry (HRMS) allows for getting a high resolved molecular weight of the compound [7]. In order to achieve a faster structural elucidation, most of the above-mentioned techniques are combined with databases [8,9]. In addition, structural elucidation is sometimes supported by Density Functional Theory (DFT) calculations to predict spectroscopic values, e.g., vibrational frequencies in IR [10] or NMR chemical shifts and couplings [11] in order to help confirming the final structure. Finally, one of the most suitable techniques for a complete molecular structure elucidation is Nuclear Magnetic Resonance (NMR) spectroscopy. Indeed, NMR spectroscopy offers accurate information on the chemical environment of all atoms in a molecule through chemical shifts, while providing crucial input on atomic connectivities through J-couplings.

There are two possible scenarios in which NMR can contribute. If the NPS is already known, the guidelines from the scientific working group for the analysis of the seized drugs (SWGDRUGS) present a resourceful strategy to reach identification [12]. They categorize analytical techniques into three groups depending on the level of selectivity they are able to achieve in the identification and quantification of pure or mixed analytes. Category $A$ techniques provide the highest level of selectivity through structural information. Category $B$ techniques provide an intermediate level of selectivity through physical or chemical characteristics without structural information whereas category $C$ techniques give rise to a low level of selectivity but provide general or chemical class information. Unambiguous structure identification requires combining two categories: at least one category $A$ technique with another from category $A, B$, or $C$. All analytical results need to be compared with those that are obtained from reference materials. For example, the analytical workflow may contain GC and MS from category $B$ and A respectively, or NMR with melting point which are from category $A$ and $C$, respectively. If the substance is totally unknown, it could be necessary to carry out a complete structural elucidation to confirm or disprove the illicit character of the molecule being studied. NMR can be a technique of choice in such case thanks to its strong structure elucidation capabilities. However, NMR is not commonly used by customs, police, or forensic labs because it is expensive to purchase and maintain, notably due to the use of cryogenic fluids. Moreover, the instrument is bulky and requires dedicated staff for maintenance.

In addition to the role NMR can play in the identification of NPS, it also has the asset of allowing quantification without resorting to a reference material identical or structurally close to the analyte. In the case of emerging molecules, such reference materials happen to be either expensive or simply not available yet.

In this context, the present review aims at highlighting the role of NMR as an analytical tool for the study of NPS, focusing both on high-field NMR and on emerging benchtop devices. Both identification and quantitation capabilities of NMR are described, as well as its complementarity to other analytical approaches in NPS structure elucidation workflows. 


\section{High Field NMR}

\subsection{NMR for structural elucidation}

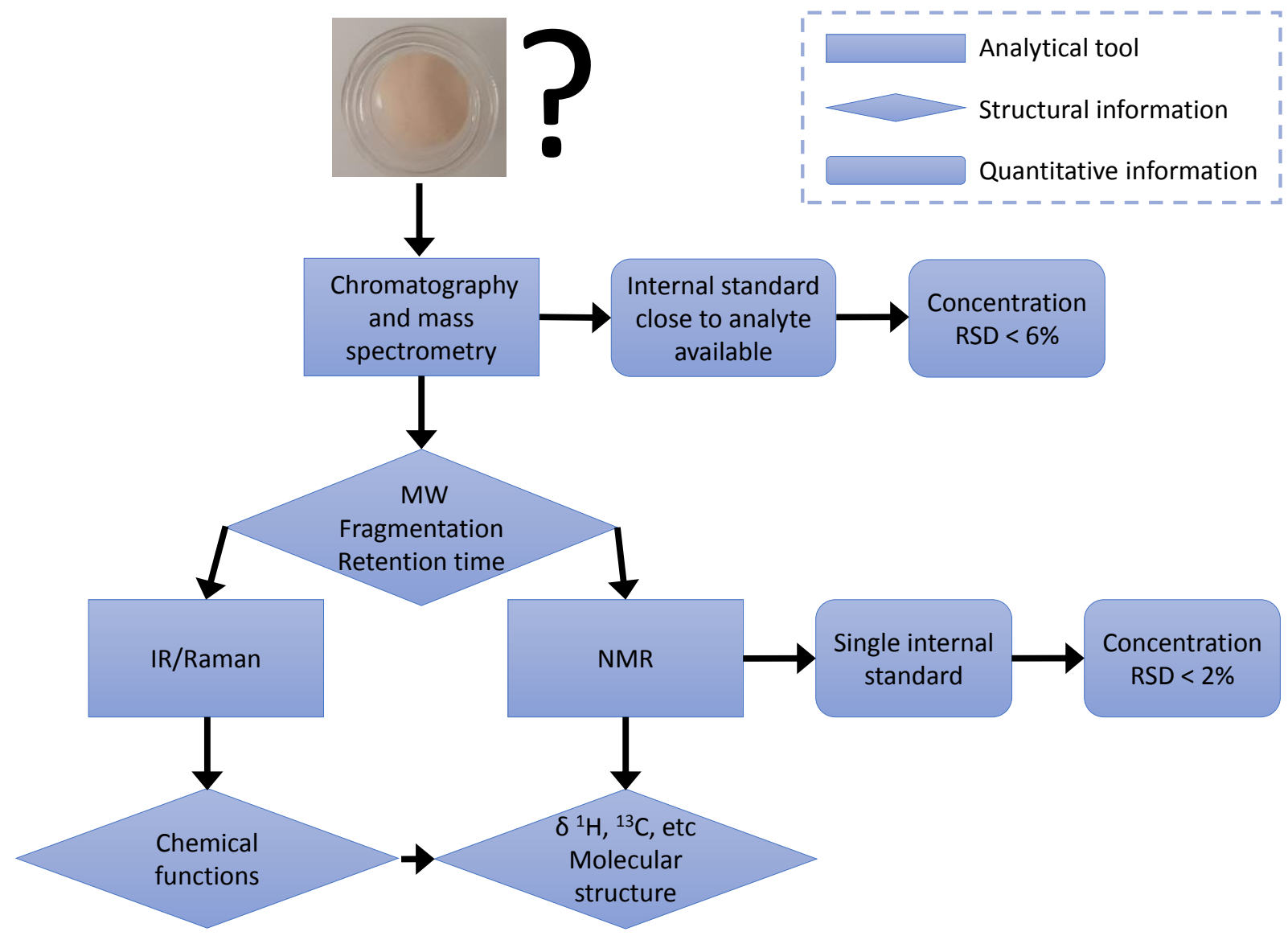

Figure 2: Flow Chart for structural and quantitative NPS analysis.

Straight rectangles describe analytical tools, rounded rectangles describe structural information obtained and rhombuses describe quantitative information.

NMR has great ability to identify and quantify small organic molecules, and is therefore essential for the structure elucidation of NPS. A first strategy consists in associating NMR spectra with databases [10]. This is particularly useful when a known molecule is suspected, but also to identify compounds in mixtures whose spectra are overlapped. In the case of unknown NPS, as for many other molecules, identification of the structure by NMR relies on a set of complementary experiments rather than on NMR alone [13]. Figure 2 shows the typical flowchart used for the structural elucidation of NPS, it is used here to support the methodology. Note that it also includes quantification aspects that are described in the next section. Structural analysis typically starts with the identification of major fragments, the determination of the molecular weight and/or the molecular formula by MS, $\mathrm{MS}^{2}$ or by GC/LCMS [6]. It can be complemented by the acquisition of IR or Raman spectra to determine the main chemical functions present in the molecule [14]. In parallel, NMR analysis makes it possible to determine the exact structure of the molecule or to confirm results obtained by chromatography and $\mathrm{MS}^{2}$. 
Figure 3 details the NMR part of this structural elucidation workflow. Commonly, standard $1 D$ and $2 D$ experiments are needed for the complete structural characterization of the molecule. One dimensional (1D) proton-1 $\left({ }^{1} \mathrm{H}\right)$ spectra are often supplemented by carbon-13 $\left({ }^{13} \mathrm{C}\right)$ spectra through direct or indirect detection. The latter, based on DEPT or INEPT experiments, offers higher sensitivity and spectral editing information allowing to identify the degree of protonation of carbons, while the former, although less sensitive, is required to detect quaternary carbons. In addition, in the case of mixtures, the larger spectral range of ${ }^{13} \mathrm{C}$ can help improve separating molecules whose ${ }^{1} \mathrm{H}$ NMR signals are overlapped. Then, the acquisition of 2D spectra provides information on through-bond or space atomic connectivities. Most popular experiments include ${ }^{1} \mathrm{H}-{ }^{1} \mathrm{H}$ homonuclear correlated SpectroscopY (COSY) to determine the neighboring ${ }^{1} \mathrm{H}$. Next, ${ }^{1} \mathrm{H}-{ }^{13} \mathrm{C}$ Heteronuclear bidimensional (2D) experiments such as Heteronuclear Single Quantum Correlation (HSQC) help determining the ${ }^{13} \mathrm{C}$ directly bearing ${ }^{1} \mathrm{H}$ in the molecule. Finally, $2 \mathrm{D}{ }^{1} \mathrm{H}-{ }^{13} \mathrm{C}$ Heteronuclear Multiple Bond Correlation ( $\mathrm{HMBC}$ ) experiments correlate long range ${ }^{1} \mathrm{H}$ and ${ }^{13} \mathrm{C}$ that are separated by two, three and four bonds (Figure 2). Despite the lower sensitivity of heteronuclear experiments coming from the selection of ${ }^{1} \mathrm{H}-{ }^{13} \mathrm{C}$ isotopomers at natural abundance, these techniques are the most informative for the structure since they correlate short and long range coupled ${ }^{1} \mathrm{H}$ and ${ }^{13} \mathrm{C}$ nuclei in the molecule. When the molecule is flexible, it may be important to access its 3D structure, which is possible through the Nuclear Overhauser Effect SpectroscopY (NOESY) or the Rotating frame Overhauser Effect SpectroscopY (ROESY) techniques [14]. For instance, those techniques can be used to determine the $Z$ or $E$ configuration of an alkene, the relative configuration of asymmetric carbons $(R, S)$, while they can also provide evidence for the conformational mobility of the structure.

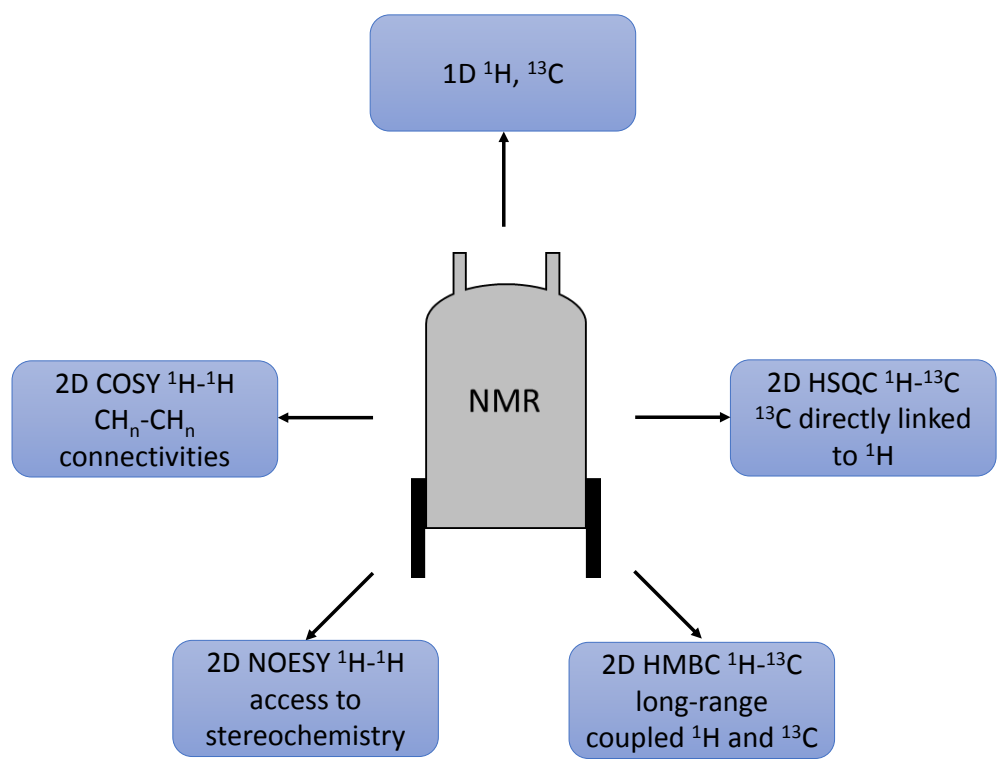

Figure 3: NMR pulse sequences commonly used to elucidate NPS molecular structures

The above mentioned workflows have been applied multiple times to elucidate the structure of NPS. While chromatography and mass spectrometry are most often used in complementarity with NMR, IR and Raman spectroscopies are rather used as optional tools, and little details are given in the literature [14-16]. 
First, NMR can be used to identify a molecule or a mixture of molecules. This approach was reported by Gibbons et al. [17] to identify compounds in a legal high, i.e., a NPS from plant or fungal material. ESI HRMS was first used to provide the accurate molecular weight hence the exact molecular formula. Then, ${ }^{1} \mathrm{H}$ and ${ }^{13} \mathrm{C}$ NMR spectra were applied to determine the purity of NPS. Finally, 2D pulse sequences were acquired for an unambiguous assignment of all carbons and hydrogens of the molecule leading to mephedrone. In another study, Lobo Vicente et al. implemented the entire workflow sketched in Figure 2. They took advantage of GC-MS, FTIR, NMR, HR-MS/MS and Raman spectroscopy on two powders found in a box from China, and the NPS could be identified as 5F-AMB and PX-3, two synthetic cannabinoids [6].

In addition to this typical workflow, NMR is often used to differentiate isomers of constitution, i.e., molecules having the same molecular formula but different structures. This approach is particularly useful to elucidate NPS in seized samples since traffickers are diverting known active moieties into unscheduled molecules, by creating small cheap structural modifications like isomerizations. For instance, Marino et al. used ${ }^{1} \mathrm{H}$ NMR in combination with Direct Analysis in Real Time Mass Spectrometry (DART-MS) to determine the structure of synthetic cannabinoids in herbals [3]. DART-MS produced a spectrum of the molecular ions indicating how many species were present in the sample, and their fragmentation schemes allowed confirming the presence of specific structural features as well as their molecular formula thanks to the exact mass. DART-MS allows to work directly on the sample with no need to dissolve it, however this technique is not always able to differentiate two isomers with identical fragments. Thus, in this example, the authors were able to reveal a naphtyl atropisomerism by comparing the NMR spectral fingerprints of herbal products containing NPS powder and pure standards. Strano et al. [7] applied a similar strategy to identify different classes of seized drugs. In this case, the differentiation of positional isomers of aminopropyl was carried out with the help of $\mathrm{J}_{\mathrm{HH}}$ coupling constants in the aromatic ${ }^{1} \mathrm{H}$ spectral region.

In some cases, the information obtained from ${ }^{1} \mathrm{H}$ NMR spectra can be limited by spectral overlap resulting from complex mixtures. Nevertheless, Bottineli et al. [18] showed that $1 \mathrm{D}^{1} \mathrm{H}$ and ${ }^{13} \mathrm{C}$ acquisitions made it possible to identify 4-FA and 2-FMA which are one of the three positional isomers of fluoroamphetamine and fluoromethamphetamine, respectively. In most cases, it is preferable to rely on 2D correlation-based experiments. For instance, Westphal et al. showed how COSY made it possible to locate the position of the methylenedioxy group of pentylone but also the unbranched side chain of pentedrone [15]. The same authors also demonstrated that the COSY map allows the identification of the position of the alkyl chain for isopentedrone. While 2D homonuclear experiments facilitate structural elucidation, there are even more resolutive and informative techniques, such as ${ }^{13} \mathrm{C}$ based-heteronuclear acquisitions. For example, Angerer et al. made a full characterization of a new synthetic cannabinoid called JWH-018 by recording a series of NMR spectra: $1 \mathrm{D}-{ }^{1} \mathrm{H},{ }^{13} \mathrm{C}$ NMR, 1D- Total Correlated SpectroscopY (TOCSY), 1D-ROESY, 2D ${ }^{1} \mathrm{H}-{ }^{1} \mathrm{H}$ COSY, ${ }^{1} \mathrm{H}-{ }^{13} \mathrm{C} \mathrm{HSQC}$, and ${ }^{1} \mathrm{H}-{ }^{13} \mathrm{C}$ HMBC [14]. In the case of NPS, 2D NOESY was also used to determine the positional isomer (out of six possibilities) of a previously unknown molecule [19] or to prove a iodo substitution [20]. 


\subsection{NMR as an accurate quantitative tool}

In parallel to structural elucidation, NMR has the ability to accurately quantify the different compounds present in NPS samples. Quantification of NPS can bring important information on sample origin, especially when the active molecule is mixed with other NPS or cutting agents such as ibuprofen, caffeine, sugars, etc. [21]. In addition, it allows official organizations such as EMCDDA (European Monitoring Centre for Drugs and Drug Addiction) to warn about the toxicity of the products and to track the drug trafficking networks. Chromatography coupled with MS is the gold standard analytical method in forensic laboratories for the quantification of seized samples of illicit drugs. However, NMR stands as an interesting alternative since: i) quantification can be achieved without physical separation of the sample components; ii) multiple compounds can be quantified with a single internal reference which does not necessarily have to be close to the analyte in contrast to chromatography; and iii) NMR yields a better accuracy, typically $2 \%$ vs $6 \%$ for GC [22] (cf. Figure 2). There are several possibilities to quantify molecules in a sample. The mass or concentration of a compound can be determined from the reference concentration:

$\operatorname{Amount}(\mathrm{mg} / \mathrm{g})=[\mathrm{REF}] \times \frac{A_{\mathrm{x}}}{A_{\mathrm{REF}}} \times \frac{N_{\mathrm{REF}}}{N_{\mathrm{x}}} \times V \times \frac{M_{\mathrm{X}}}{m_{\text {sample }}}$

in which, $[\mathrm{REF}]$ is the concentration of the internal standard (mol/L), $A_{\mathrm{x}}$ the integral of the analyte signal, $A_{\mathrm{REF}}$ the integral of the reference signal, $N_{\mathrm{REF}}$ the number of reference protons, $N_{\mathrm{x}}$ the number of analyte protons, $V$ the volume of the solution (L), $M_{\mathrm{x}}$ the molecular weight of the analyte $(\mathrm{mg} / \mathrm{mol})$, and $m_{\text {sample }}$ the mass of sample $(\mathrm{g})$.

Moreover, it is also possible to determine the purity by taking into account the purity of the reference:

$P_{\text {sample }}=\frac{A_{\mathrm{x}}}{A_{\mathrm{REF}}} \times \frac{N_{\mathrm{REF}}}{N_{\mathrm{x}}} \times \frac{M_{\mathrm{x}}}{M_{\mathrm{REF}}} \times \frac{m_{\mathrm{REF}}}{m_{\text {sample }}} \times P_{\mathrm{REF}}$,

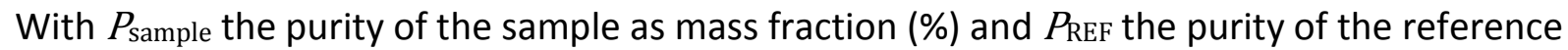
as mass fraction (\%).

These strategies have been used in different studies involving NPS. For instance, Eq. 1 was applied to precisely determine amounts of synthetic cannabinoids in a complex herbal mixtures [23]. Concentrations were determined by comparing the areas of targeted protons to the ones of dimethyl maleate as an internal reference with precise known concentration. NMR was also applied to determine the mass of psychoactive product in a tablet. Naqi et al. quantified seized MDMA by using ${ }^{1} \mathrm{H}$-qNMR, UHPLC and UHPLC-MS (Table 1) [24]. Maleic acid and MDMA-d5 were used respectively as an internal reference for NMR and UHPLC measurements. The MDMA concentrations determined by UHPLC and NMR were found comparable with no significant statistical difference as revealed by ANOVA single factor analysis. 
Table 1: UHPLC, NMR and UHPLC-MS quantitative results of MDMA tablet. [24] - Reproduced with permission of the Royal Society of Chemistry.

\begin{tabular}{|c|c|c|c|c|c|c|c|c|}
\hline No & \multicolumn{4}{|c|}{ UHPLC } & \multicolumn{2}{c|}{ NMR } & \multicolumn{2}{c|}{ UHPLC-MS } \\
\hline 4 & Entry & $\begin{array}{c}\text { Weight } \\
(\mathrm{mg})\end{array}$ & $\begin{array}{c}\text { MDMA } \\
\text { dose } \\
(\mathrm{mg}) \pm \mathrm{SD}\end{array}$ & RSD\% & $\begin{array}{c}\text { MDMA } \\
\text { dose } \\
(\mathrm{mg}) \pm \mathrm{SD}\end{array}$ & RSD\% & $\begin{array}{c}\text { MDMA } \\
\text { dose } \\
(\mathrm{mg}) \pm \mathrm{SD}\end{array}$ & RSD\% \\
\hline \multirow{2}{*}{$\mathrm{a}$} & 512.73 & $160.55 \pm 0.8$ & 0.5 & $164.21 \pm 0.4$ & 0.3 & $161.07 \pm 4.7$ & 2.9 \\
\cline { 2 - 9 } & $\mathrm{b}$ & 481.95 & $150.27 \pm 2.4$ & 1.6 & $151.92 \pm 2.1$ & 1.4 & $153.80 \pm 8.6$ & 5.6 \\
\hline
\end{tabular}

In another study, Eq. 2 allowed determining the purity of the compounds present in mixtures of NPS or cutting agents (vitamins, caffeine, etc.) [25]. Finally, the case of a 41-yearold man known as a polydrug addict and found dead at home was resolved by resorting to NMR [26]. Seven small bags of unknown powders and crystals, suspected to be NPS, were found close to the body and sent to the laboratory 3 weeks later. A complete structural elucidation was carried out with $1 \mathrm{D}{ }^{1} \mathrm{H}$ and ${ }^{13} \mathrm{C}$ spectra, DEPT ${ }^{13} \mathrm{C}$ spectra, and a set of 2D experiments including ${ }^{1} \mathrm{H}-{ }^{1} \mathrm{H}$ COSY, edited ${ }^{1} \mathrm{H}-{ }^{13} \mathrm{C} \mathrm{HSQC}$, and ${ }^{1} \mathrm{H}-{ }^{13} \mathrm{C}$ HMBC. ${ }^{19} \mathrm{~F}$ experiments were performed as well. Moreover, NPS were quantified and their purity was determined thanks to Eq. 2 using maleic acid as an internal reference. This investigation revealed that the purity of the recovered compounds was between 50.8 and $89.5 \%$, which is within the usual range of products seized in Europe $[27,28]$.

In short, NMR can be seen as a new gold standard for quantification since it does not require the use of a structurally close reference to the analyte and leads to a lower RSD than chromatography. In addition, it remains a non-destructive technique and allows to quantify multiple compounds in a sample at the same time.

\section{Benchtop NMR spectroscopy}

\subsection{Advantages and drawbacks}

Despite the above-mentioned advantages, NMR is not yet a routine tool in forensics due to both the bulky and expensive high-field equipment and to the need to fill magnets with cryogenic fluids. An alternative could emerge from medium-field benchtop NMR spectrometers that do not suffer from such drawbacks. Benchtop NMR spectroscopy represents a major advance in quality control since it is transportable and can therefore be directly positioned in production sites. It has already been used for the study of adulteration of oils [29], dietary supplements [30] and meat [31], but also to monitor chemical reactions [32] or bioprocesses [33]. Whereas high field NMR instruments operate above $300 \mathrm{MHz}$, commercial compact NMR spectrometers operate at ${ }^{1} \mathrm{H}$ frequencies between 40 and $100 \mathrm{MHz}$. Moreover, these benchtop spectrometers are characterized by excellent homogeneity, comparable to the one of high-field spectrometers. However, two issues stem from such low magnetic fields: a lower sensitivity but also a reduction of the spectral resolution arising from the much lower spectral width in $\mathrm{Hz}$. Figure 4 illustrates how lower magnetic fields lead to poorly resolved spectra, making it difficult to identify multiplet patterns. This issue is further complicated by second order coupling effects that appear when the chemical shift difference in $\mathrm{Hz}$ between coupled spins becomes of the same order of magnitude as the coupling constant between those sites. Second order couplings strongly distort multiplet intensities 
and increase when the magnetic field decreases, since the resonance frequencies become closer whilst the J-couplings are invariant with magnetic field.

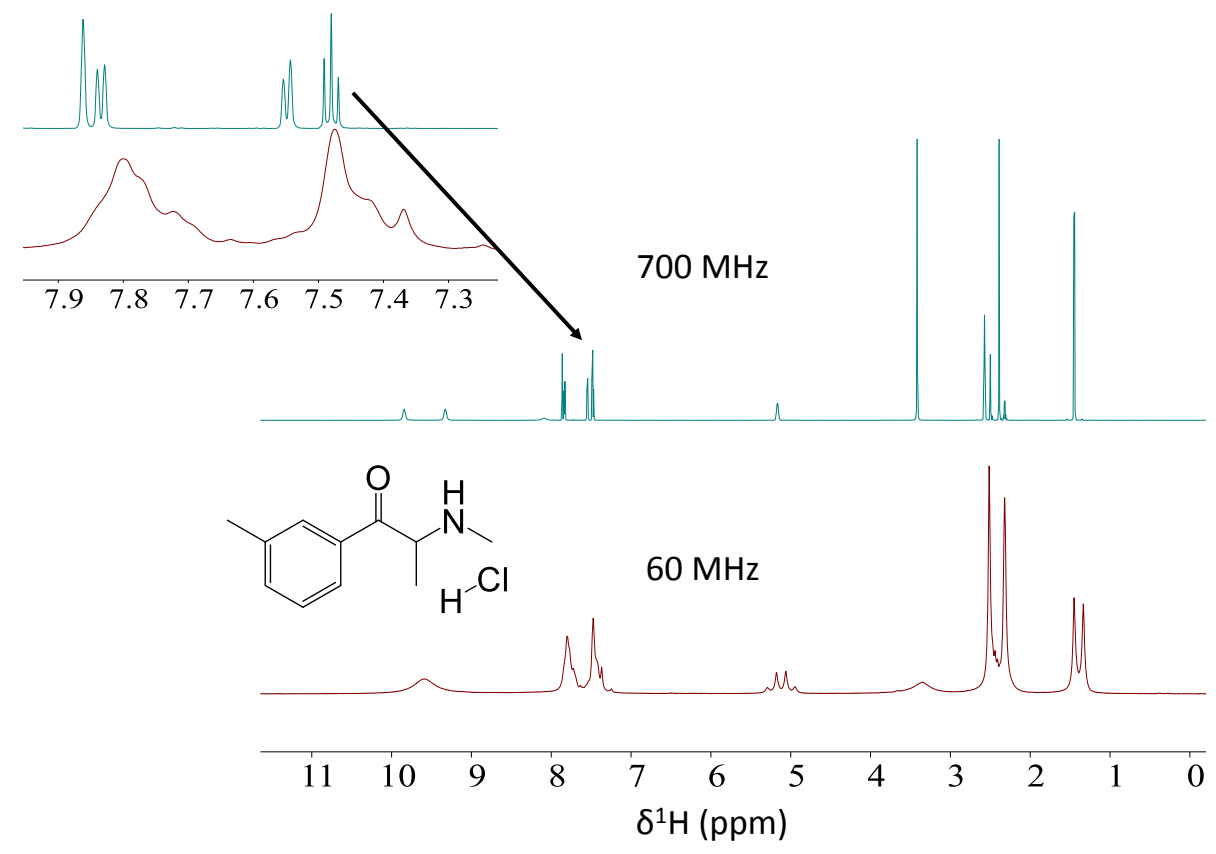

Figure 4: NMR spectra of 3-MMC at $60 \mathrm{MHz}$ and $700 \mathrm{MHz}$.

\subsection{Application to NPS}

To the best of our knowledge, no full structural elucidation of NPS has been reported yet on a benchtop spectrometer. However, some results show that for some average-sized compound like strychnine, structure determination is feasible. In reference [34], authors showed that by recording of $1 \mathrm{D}{ }^{1} \mathrm{H}, 1 \mathrm{D}{ }^{13} \mathrm{C}, 2 \mathrm{D}$ J-resolved, ${ }^{1} \mathrm{H}-{ }^{1} \mathrm{H}$ COSY, ${ }^{1} \mathrm{H}^{13} \mathrm{C}$ HETeronuclear CORrelation (HETCOR), ${ }^{1} \mathrm{H}-{ }^{13} \mathrm{C}$ HSQC, and ${ }^{1} \mathrm{H}-{ }^{13} \mathrm{C}$ HMBC spectra, the redundant information counterbalances the lack of information induced by the low resolution (Figure 5).
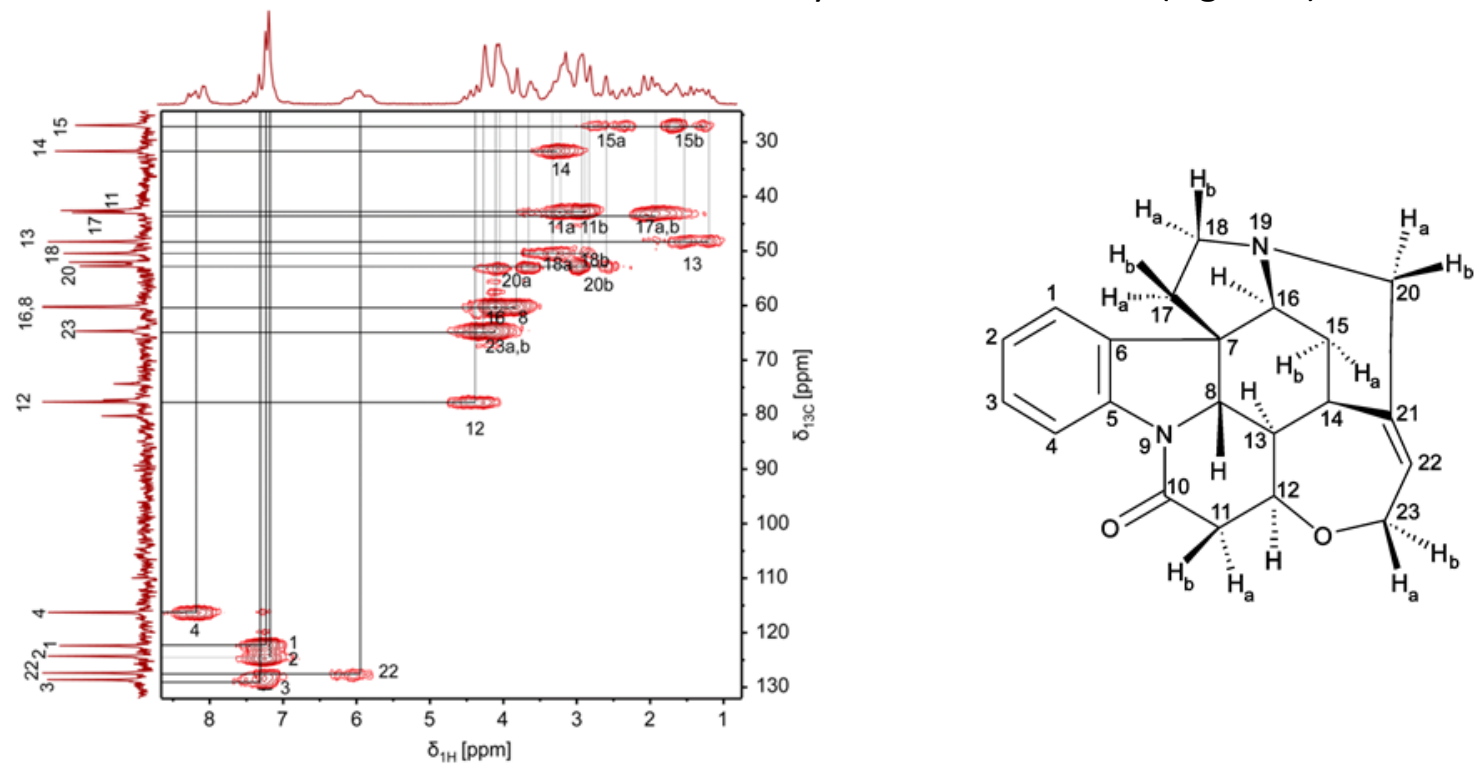

Figure 5: 2D HSQC spectrum of strychnine $(135 \mathrm{mM})$ dissolved in $\mathrm{CDCl}_{3}$ recorded with 128 scans in 22.7 hours at 1 Tesla. Reproduced from Ref. [34] with permission. 
Molecular databases could offer a complementary efficient strategy to circumvent spectral resolution issues that prevent the use of benchtop NMR to elucidate the structure of NPS. A convincing example relates to the development of an automated algorithm for spectral recognition of NPS [35]. ${ }^{1} \mathrm{H}$ NMR spectra of reference compounds were collected using an $80 \mathrm{MHz}$ instrument. The reference library consists of 302 spectra altogether for different classes of NPS. Then 432 seized samples were analyzed by NMR and GC-MS for cross validation. ${ }^{1} \mathrm{H}$ NMR analysis nicely matched the GC-MS results for $93 \%$ of the cases. This example highlights the relevance of combining benchtop NMR with databases, and that such combination can be made even more efficient when databases encompass high field NMR data. Capitalizing on such a strategy, Duffy et al. analyzed several fentanyls at different magnetic fields [36]. In order to deal with second order coupling effects that make the comparison of data acquired at different fields challenging, these authors relied on a Quantum Mechanical Spectral Analysis (QMSA) to transform spectra obtained at high field into their benchtop NMR counterpart. This approach was efficient in retrieving structural data from benchtop spectra despite signal overlaps and strong couplings. It also highlights the trends going to the generalization of databases for NPS structure elucidation.

Quantification is also possible with medium-field NMR, although rendered more difficult by strong peak overlaps. Under this situation, it becomes necessary to use an internal reference having isolated characteristic signals. In the field of pharmaceutics, active substances such as acetaminophen, aspirin, diclofenac, ibuprofen, and naproxen were quantified by NMR spectroscopy and compared to those obtained by LC-QTOF-MS (Table 2). The two techniques offered comparable results with a better accuracy for NMR than for LCQTOF-MS in most cases [37].

Table 2: Quantitation of over-the-counter pharmaceutical products, using benchtop ${ }^{1} \mathrm{H}-\mathrm{NMR}$ spectroscopy, using 3,4,5-trichloropyridine as internal standard and LC-QTOF-MS. The NMR analyses were performed with

five independent measurements, the LC-MS analyses were performed with two dose units measured in duplicate. Reprinted from [37] with permission from Elsevier.

\begin{tabular}{|c|c|c|c|}
\hline $\begin{array}{l}\text { Phamaceutical } \\
\text { product }\end{array}$ & $\begin{array}{l}\text { Declared dose } \\
\text { (mg per dose } \\
\text { unit }\end{array}$ & $\begin{array}{l}\text { Dose determined by benchtop } \\
\text { NMR } \\
\text { spectroscopy (mg per dose unit) }\end{array}$ & $\begin{array}{l}\text { Dose determined by LC-QTOF- } \\
\text { MS } \\
\text { (mg per dose unit) }\end{array}$ \\
\hline $\begin{array}{l}\text { Acetaminophen } \\
\text { Lot: } 3043510 \\
\text { Exp. } 08-2022\end{array}$ & 500 & $523 \pm 7$ & $533 \pm 32$ \\
\hline $\begin{array}{l}\text { Aspirin } \\
\text { Charge: BTARJRAO } \\
\text { Exp. 01-2021 }\end{array}$ & 100 & $107 \pm 3$ & $108 \pm 30$ \\
\hline $\begin{array}{l}\text { Diclofenac } \\
\text { Lot: } 3337244 \\
\text { Exp. } 09-2020\end{array}$ & $\begin{array}{l}11 \\
12.5 \mathrm{~K} \text {-salt }\end{array}$ & $\begin{array}{l}11 \pm 0.2 \\
\text { (free base) }\end{array}$ & $\begin{array}{l}11 \pm 2 \\
\text { (free base) }\end{array}$ \\
\hline $\begin{array}{l}\text { Ibuprofen } \\
\text { Lot: } 3230694 \\
\text { Exp. 09-2022 }\end{array}$ & 200 & $211 \pm 26$ & $204 \pm 13$ \\
\hline $\begin{array}{l}\text { Naproxen } \\
\text { Lot: } 3008971 \\
\text { Exp. } 01-2022\end{array}$ & $\begin{array}{l}201 \\
\text { (220 Na-salt) }\end{array}$ & $\begin{array}{l}197 \pm 6 \\
\text { (free base) }\end{array}$ & $\begin{array}{l}240 \pm 37 \\
\text { (free base) }\end{array}$ \\
\hline
\end{tabular}


This approach could therefore be transposed to the quantification of NPS with no need to find a chromatographic reference from the same family than the molecule of interest.

\subsection{Perspectives}

While benchtop NMR spectroscopy offers promising perspectives for structure elucidation and quantification of NPS at a reasonable cost, the applicability of this technique remains limited by the above-mentioned resolution and sensitivity issues. Promising perspectives could arise from pulse sequence developments that have recently emerged to improve the performance of benchtop devices, based on the addition of magnetic field gradient coil an essential ingredient of pulse sequence developments in high-field NMR for decades. Such developments include ultrafast 2D NMR [38] allowing the acquisition of singlescan 2D spectra, pure shift sequences [39] enabling to remove $\mathrm{J}_{H H}$ couplings, or 2D DOSY [40] which provides virtual separation of mixture components based on their diffusion coefficients. Moreover, hyperpolarization techniques like parahydrogen based methods $[41,42]$ could also be advantageous in order to reach spectra with an overall better sensitivity for investigating lower amounts of NPS in mixtures, although routine application would require a level of automation that is currently not reach with such methods.

DFT-based simulations [43] may also play a role in facilitating structural elucidation at low magnetic fields. DFT methods are a subgroup of $a b$ initio theories generally considered as the best in terms of accuracy/cost ratio. DFT allows calculating chemical shifts and scalar couplings for all atoms of a given molecule in one shot, possibly accounting for solvent effects during the calculations. DFT can also be combined with machine learning algorithms to reduce the time needed to predict chemical shifts [43].

\section{Conclusions}

NMR spectroscopy plays a strategic role in the characterization and quantification of NPS. Most of the time, NMR is used in combination with other analytical techniques to cross-check, confirm, and validate integrated reliable data regarding the molecular structure. Characterization usually requires chromatography coupled with mass spectrometry to determine the molecular weight and the molecular formula of the structure as a starting point to perform any NMR elucidation. Moreover, IR could also bring complementary data of interest to confirm the presence of specific chemical functions.

Benchtop NMR could act as a new game changer in the analysis of NPS in police, customs and forensic laboratories despite its lower resolution. Indeed, it is associated with lower purchase and operating costs, allowing more laboratories to be equipped with NMR. However, benchtop NMR requires pushing further the development of new acquisition methods and integrating NMR with other analytical methods, DFT calculations, and/or databases.

A foreseen analytical workflow (Figure 6) would include the use of a portable platform with medium field NMR equipped with a gradient coil for implementing advanced methods on an 80 to $100 \mathrm{MHz}$ benchtop NMR spectrometer, together with DART-MS, and IR. This integrated platform could be enhanced with databases of all NPS encountered throughout the world as well as machine learning prediction to improve accuracy and speed of elucidation. 


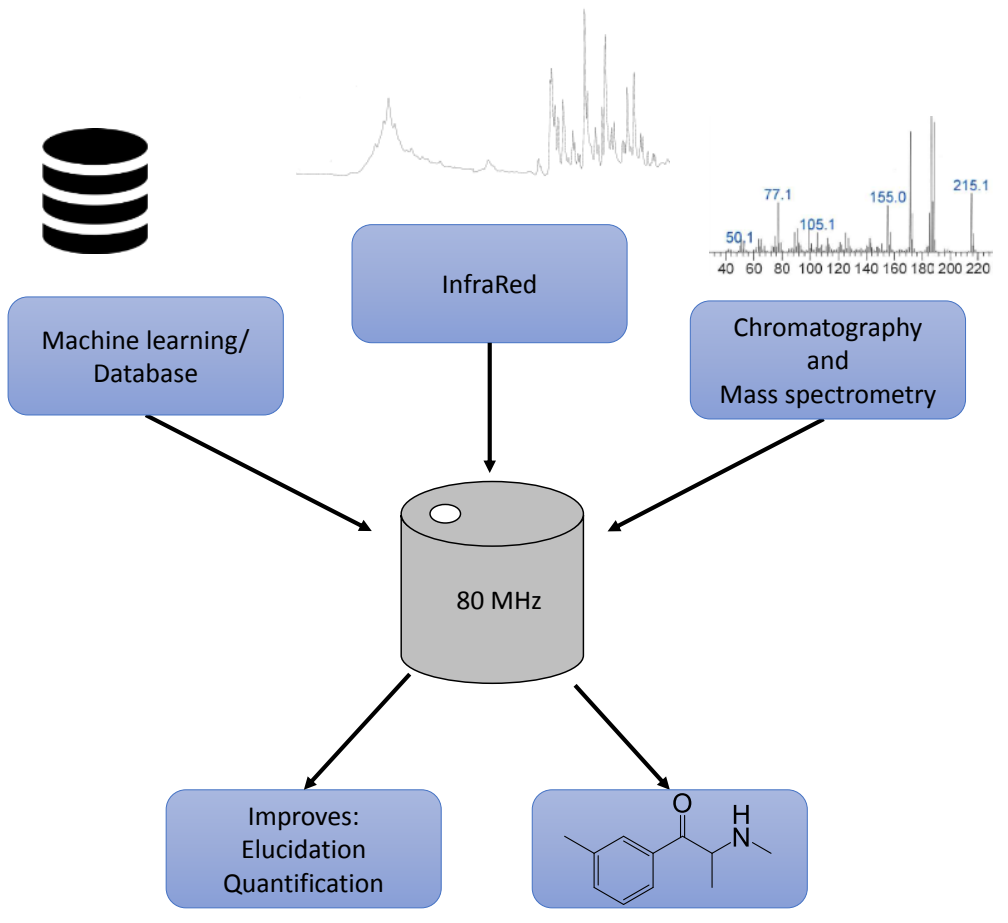

Figure 6: Future of NPS identification. 
References:

[1] What are NPS?, (n.d.). https://www.unodc.org/LSS/Page/NPS (accessed March 11, 2020).

[2] Nouveaux produits de synthèse - Synthèse des connaissances - OFDT, (2018). https://www.ofdt.fr/produits-et-addictions/de-z/nouveaux-produits-de-synthese/\#rlr (accessed March 11, 2020).

[3] M.A. Marino, B. Voyer, R.B. Cody, A.J. Dane, M. Veltri, L. Huang, Rapid Identification of Synthetic Cannabinoids in Herbal Incenses with DART-MS and NMR, J. Forensic Sci. 61 Suppl 1 (2016) S82-91. https://doi.org/10.1111/1556-4029.12932.

[4] J. Omar, B. Slowikowski, C. Guillou, F. Reniero, M. Holland, A. Boix, Identification of new psychoactive substances (NPS) by Raman spectroscopy, Journal of Raman Spectroscopy. 50 (2019) 41-51. https://doi.org/10.1002/jrs.5496.

[5] M.P. Elie, L.E. Elie, M.G. Baron, Keeping pace with NPS releases: fast GC-MS screening of legal high products, Drug Testing and Analysis. 5 (2013) 281-290. https://doi.org/10.1002/dta.1434.

[6] J. Lobo Vicente, H. Chassaigne, M.V. Holland, F. Reniero, K. Kolář, S. Tirendi, I. Vandecasteele, I. Vinckier, C. Guillou, Systematic analytical characterization of new psychoactive substances: A case study, Forensic Science International. 265 (2016) 107-115. https://doi.org/10.1016/j.forsciint.2016.01.024.

[7] S. Strano Rossi, S. Odoardi, A. Gregori, G. Peluso, L. Ripani, G. Ortar, G. Serpelloni, F.S. Romolo, An analytical approach to the forensic identification of different classes of new psychoactive substances (NPSs) in seized materials, Rapid Commun. Mass Spectrom. 28 (2014) 1904-1916. https://doi.org/10.1002/rcm.6969.

[8] B.J. Dçebska, B. Guzowska-Świder, Spectral Databases, Infrared, in: Encyclopedia of Analytical Chemistry, American Cancer Society, 2006. https://doi.org/10.1002/9780470027318.a5612.

[9] P. Ausloos, C.L. Clifton, S.G. Lias, A.I. Mikaya, S.E. Stein, D.V. Tchekhovskoi, O.D. Sparkman, V. Zaikin, D. Zhu, The critical evaluation of a comprehensive mass spectral library, Journal of the American Society for Mass Spectrometry. 10 (1999) 287-299. https://doi.org/10.1016/S1044-0305(98)00159-7.

[10] M. Ali, A. Mansha, S. Asim, M. Zahid, M. Usman, N. Ali, DFT Study for the Spectroscopic and Structural Analysis of p-Dimethylaminoazobenzene, Journal of Spectroscopy. 2018 (2018) e9365153. https://doi.org/10.1155/2018/9365153.

[11] A. Bagno, F. Rastrelli, G. Saielli, Predicting 13C NMR Spectra by DFT Calculations, J. Phys. Chem. A. 107 (2003) 9964-9973. https://doi.org/10.1021/jp0353284.

[12] SWGDRUG Approved Recommendations, (2019). http://www.swgdrug.org/approved.htm (accessed September 30, 2020).

[13] V. Shevyrin, V. Melkozerov, O. Eltsov, Y. Shafran, Y. Morzherin, Synthetic cannabinoid 3-benzyl-5-[1-(2pyrrolidin-1-ylethyl)-1H-indol-3-yl]-1,2,4-oxadiazole. The first detection in illicit market of new psychoactive substances, Forensic Science International. $259 \quad$ (2016) 95-100. https://doi.org/10.1016/j.forsciint.2015.12.019.

[14] V. Angerer, P. Bisel, B. Moosmann, F. Westphal, V. Auwärter, Separation and structural characterization of the new synthetic cannabinoid JWH-018 cyclohexyl methyl derivative NE-CHMIMO using flash chromatography, GC-MS, IR and NMR spectroscopy, Forensic Science International. 266 (2016) e93-e98. https://doi.org/10.1016/j.forsciint.2016.05.031.

[15] F. Westphal, T. Junge, U. Girreser, W. Greibl, C. Doering, Mass, NMR and IR spectroscopic characterization of pentedrone and pentylone and identification of their isocathinone by-products, Forensic Science International. 217 (2012) 157-167. https://doi.org/10.1016/j.forsciint.2011.10.045.

[16] L. Böselt, R. Dötzer, S. Steiner, M. Stritzinger, S. Salzmann, S. Riniker, Determining the Regiochemistry and Relative Stereochemistry of Small and Druglike Molecules Using an Alignment Algorithm for Infrared Spectra, Anal. Chem. (2020). https://doi.org/10.1021/acs.analchem.0c01399.

[17] S. Gibbons, M. Zloh, An analysis of the 'legal high' mephedrone, Bioorganic \& Medicinal Chemistry Letters. 20 (2010) 4135-4139. https://doi.org/10.1016/j.bmcl.2010.05.065.

[18] C. Bottinelli, K. Revelut, M. Hologne, Y. Gaillard, F. Bévalot, GC-MS, GC-QTOF and NMR analyses to elucidate composition of 41 powders from an NPS collector, Toxicologie Analytique et Clinique. 31 (2019) 275-282. https://doi.org/10.1016/j.toxac.2019.10.002.

[19] F. Westphal, U. Girreser, S. Knecht, Structure elucidation of a new open chain isomer of the cannabimimetic cyclopropoylindole A-796,260, Forensic Science International. 234 (2014) 139-148. https://doi.org/10.1016/j.forsciint.2013.11.006.

[20] P. Jankovics, A. Váradi, L. Tölgyesi, S. Lohner, J. Németh-Palotás, J. Balla, Detection and identification of the new potential synthetic cannabinoids 1-pentyl-3-(2-iodobenzoyl)indole and 1-pentyl-3-(1- 
adamantoyl)indole in seized bulk powders in Hungary, Forensic Science International. 214 (2012) 27-32. https://doi.org/10.1016/j.forsciint.2011.07.011.

[21] P.A. Hays, Proton Nuclear Magnetic Resonance Spectroscopy (NMR) Methods for Determining the Purity of Reference Drug Standards and Illicit Forensic Drug Seizures, JFS. 50 (2005) JFS2005124-19. https://doi.org/10.1520/JFS2005124.

[22] N.S. Almeida, L.E.C. Benedito, A.O. Maldaner, A.L. de Oliveira, N.S. Almeida, L.E.C. Benedito, A.O. Maldaner, A.L. de Oliveira, A Validated NMR Approach for MDMA Quantification in Ecstasy Tablets, Journal of the Brazilian Chemical Society. 29 (2018) 1944-1950. https://doi.org/10.21577/0103-5053.20180071.

[23] G. Assemat, F. Dubocq, S. Balayssac, C. Lamoureux, M. Malet-Martino, V. Gilard, Screening of "spice" herbal mixtures: From high-field to low-field proton NMR, Forensic Science International. 279 (2017) 8895. https://doi.org/10.1016/j.forsciint.2017.08.006.

[24] H.A. Naqi, S.M. Husbands, I.S. Blagbrough, $1 \mathrm{H}$ quantitative NMR and UHPLC-MS analysis of seized MDMA/NPS mixtures and tablets from night-club venues, Anal. Methods. 11 (2019) 4795-4807. https://doi.org/10.1039/C9AY01403A.

[25] H. Gaspar, S. Bronze, S. Ciríaco, C.R. Queirós, A. Matias, J. Rodrigues, C. Oliveira, C. Cordeiro, S. Santos, 4FPBP (4'-fluoro- $\alpha$-pyrrolidinobutyrophenone), a new substance of abuse: Structural characterization and purity NMR profiling, Forensic Science International. $252 \quad$ (2015) 168-176. https://doi.org/10.1016/j.forsciint.2015.05.003.

[26] A. Ameline, D. Garnier, L. Gheddar, C. Richeval, J. Gaulier, J. Raul, P. Kintz, Identification and analytical characterization of seven NPS, by combination of $1 \mathrm{H}$ NMR spectroscopy, GC-MS and UPLC-MS/MS ${ }^{\circledR}$, to resolve a complex toxicological fatal case, Forensic Science International. 298 (2019) 140-148. https://doi.org/10.1016/j.forsciint.2019.03.003.

[27] Observatoire Français des Drogues et des Toxicomanies, Drogues, chiffres clés, 6ème édition, (2015) 1-8 Juin.

[28] European Monitoring Center for Drugs and Drug Addiction, European Drug Report: Trends and Developments, EMCDDA, Lisbon, (2018). http://www.emcdda.europa.eu/system/files/publications/8585/ 20181816_TDAT18001ENN_PDF.pdf. (accessed August 25, 2020).

[29] T. Parker, E. Limer, A.D. Watson, M. Defernez, D. Williamson, E.K. Kemsley, 60MHz 1H NMR spectroscopy for the analysis of edible oils, TrAC Trends in Analytical Chemistry. 57 (2014) 147-158. https://doi.org/10.1016/j.trac.2014.02.006.

[30] G. Pagès, A. Gerdova, D. Williamson, V. Gilard, R. Martino, M. Malet-Martino, Evaluation of a Benchtop Cryogen-Free Low-Field 1H NMR Spectrometer for the Analysis of Sexual Enhancement and Weight Loss Dietary Supplements Adulterated with Pharmaceutical Substances, Anal. Chem. 86 (2014) 11897-11904. https://doi.org/10.1021/ac503699u.

[31] W. Jakes, A. Gerdova, M. Defernez, A.D. Watson, C. McCallum, E. Limer, I.J. Colquhoun, D.C. Williamson, E.K. Kemsley, Authentication of beef versus horse meat using $60 \mathrm{MHz} 1 \mathrm{H}$ NMR spectroscopy, Food Chemistry. 175 (2015) 1-9. https://doi.org/10.1016/j.foodchem.2014.11.110.

[32] B. Gouilleux, B. Charrier, E. Danieli, J.-N. Dumez, S. Akoka, F.-X. Felpin, M. Rodriguez-Zubiri, P. Giraudeau, Real-time reaction monitoring by ultrafast 2D NMR on a benchtop spectrometer, Analyst. 140 (2015) 7854-7858. https://doi.org/10.1039/C5AN01998B.

[33] D. Bouillaud, V. Heredia, T. Castaing-Cordier, D. Drouin, B. Charrier, O. Gonçalves, J. Farjon, P. Giraudeau, Benchtop flow NMR spectroscopy as an online device for the in vivo monitoring of lipid accumulation in microalgae, Algal Research. 43 (2019) 101624. https://doi.org/10.1016/j.algal.2019.101624.

[34] K. Singh, B. Blümich, Desktop NMR for structure elucidation and identification of strychnine adulteration, Analyst. 142 (2017) 1459-1470. https://doi.org/10.1039/C7AN00020K.

[35] L.H. Antonides, R.M. Brignall, A. Costello, J. Ellison, S.E. Firth, N. Gilbert, B.J. Groom, S.J. Hudson, M.C. Hulme, J. Marron, Z.A. Pullen, T.B.R. Robertson, C.J. Schofield, D.C. Williamson, E.K. Kemsley, O.B. Sutcliffe, R.E. Mewis, Rapid Identification of Novel Psychoactive and Other Controlled Substances Using Low-Field 1H NMR Spectroscopy, ACS Omega. 4 (2019) 7103-7112. https://doi.org/10.1021/acsomega.9b00302.

[36] J. Duffy, A. Urbas, M. Niemitz, K. Lippa, I. Marginean, Differentiation of fentanyl analogues by low-field NMR spectroscopy, Analytica Chimica Acta. $1049 \quad$ (2019) 161-169. https://doi.org/10.1016/j.aca.2018.12.014.

[37] P.H.J. Keizers, F. Bakker, J. Ferreira, P.F.K. Wackers, D. van Kollenburg, E. van der Aa, A. van Beers, Benchtop NMR spectroscopy in the analysis of substandard and falsified medicines as well as illegal drugs, Journal of Pharmaceutical and Biomedical Analysis. 178 (2020) 112939. https://doi.org/10.1016/j.jpba.2019.112939. 
[38] B. Gouilleux, J. Marchand, B. Charrier, G.S. Remaud, P. Giraudeau, High-throughput authentication of edible oils with benchtop Ultrafast 2D NMR, Food Chemistry. 244 (2018) 153-158. https://doi.org/10.1016/j.foodchem.2017.10.016.

[39] T. Castaing-Cordier, D. Bouillaud, P. Bowyer, O. Gonçalves, P. Giraudeau, J. Farjon, Highly Resolved PureShift Spectra on a Compact NMR Spectrometer, ChemPhysChem. 20 (2019) 736-744. https://doi.org/10.1002/cphc.201801116.

[40] G. Assemat, B. Gouilleux, D. Bouillaud, J. Farjon, V. Gilard, P. Giraudeau, M. Malet-Martino, Diffusionordered spectroscopy on a benchtop spectrometer for drug analysis, Journal of Pharmaceutical and Biomedical Analysis. 160 (2018) 268-275. https://doi.org/10.1016/j.jpba.2018.08.011.

[41] A.D. Robinson, P.M. Richardson, M.E. Halse, Hyperpolarised $1 \mathrm{H}-13 \mathrm{C}$ benchtop NMR spectroscopy, Applied Sciences. (2019). http://eprints.whiterose.ac.uk/143732/ (accessed February 19, 2020).

[42] T.B.R. Robertson, L.H. Antonides, N. Gilbert, S.L. Benjamin, S.K. Langley, L.J. Munro, O.B. Sutcliffe, R.E. Mewis, Hyperpolarization of Pyridyl Fentalogues by Signal Amplification By Reversible Exchange (SABRE), ChemistryOpen. 8 (2019) 1375-1382. https://doi.org/10.1002/open.201900273.

[43] W. Gerrard, L.A. Bratholm, M.J. Packer, A.J. Mulholland, D.R. Glowacki, C.P. Butts, IMPRESSION - prediction of NMR parameters for 3-dimensional chemical structures using machine learning with near quantum chemical accuracy, Chem. Sci. 11 (2020) 508-515. https://doi.org/10.1039/C9SC03854J. 